http://jmscr.igmpublication.org/home/

ISSN (e)-2347-176x ISSN (p) 2455-0450

crossref DOI: https://dx.doi.org/10.18535/jmscr/v7i11.64

\title{
The Tale of an Accidental Bullet Injury: Lucky Escape for an Otherwise Unlucky Child
}

\author{
Authors \\ Dr Vipan Garg', Dr Summit Bloria ${ }^{2 *}$, Dr Anju Bala ${ }^{3}$ \\ ${ }^{1}$ Junior Resident, Department of Anaesthesia and Intensive Care, PGIMER Chandigarh \\ ${ }^{2}$ Senior Resident Neuroanaesthesia, Department of Anaesthesia and Intensive Care, PGIMER Chandigarh \\ ${ }^{3}$ Junior Resident, Department of Pediatrics, DR. RPGMC Tanda \\ *Corresponding Author \\ Dr Summit Bloria \\ Senior Resident Neuroanaesthesia, Department of Anaesthesia and Intensive Care, PGIMER Chandigarh
}

Abstract
The use of Fire arms can lead to severe injuries and can lead to death. The harm caused by a bullet
depends on a multitude of factors, including the path travelled by the bullet, velocity of bullet when it came
in contact with the person and the damage caused by it to the tissues it travelled through. A bullet injury to
head is in most cases severe and can cause instant death.
Keywords: Bullet, injury, death.

\section{Case Report}

We report the anaesthetic management of a 10 year old female child who accidently suffered from penetrating brain trauma due to a bullet injury and was subsequently operated for the removal of same.

Child was playing near her house in open one afternoon when she felt sudden pain in head, severe in intensity along with minimal bleeding from scalp on left side. There were no episodes of loss of consciousness, vomiting, seizures or any other neurological deficit in the child. The parents of the child then took her to a nearby hospital where she was advised an x-ray and CT scan of head to determine the cause of headache and to rule out any intracranial pathology. The CT scan and the x-ray (Figure 1) to the surprise of everyone demonstrated presence of foreign body(bullet) in left occipital lobe. The bullet was most probably fired in air and had entered the brain of child on its way down to earth while she was playing in open. She was referred to our institution where it was decided upon to operate on the patient.

Images 1 (x ray) shows presence of bullet inside skull.




Images 2 (x ray) shows presence of bullet inside skull.

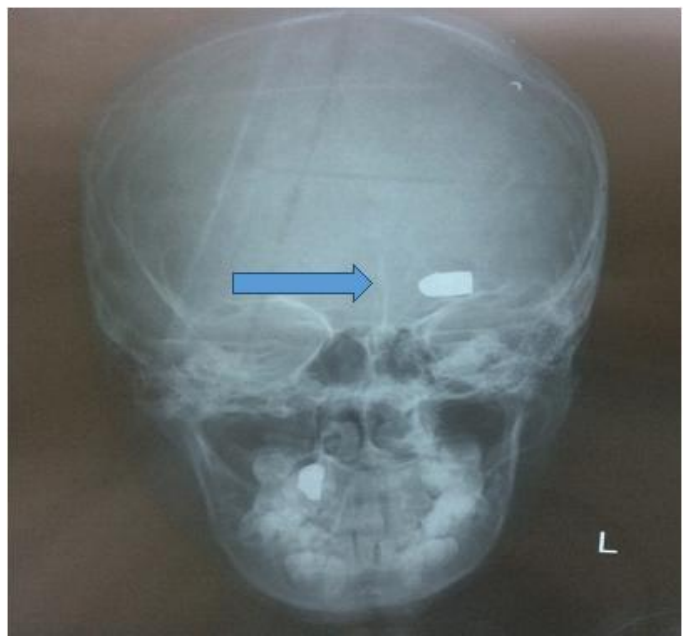

Images 3 (CT image) shows presence of Metallic object inside Brain Parenchyma.

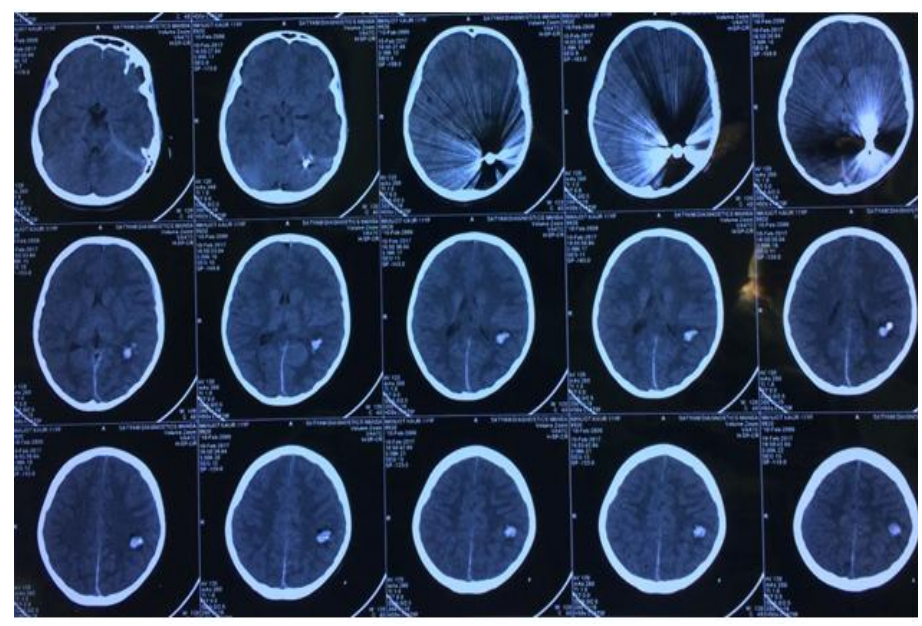

Examination: We first met the patient for preanaesthetic check-up. She was conscious and oriented to time, place and person. There were no neurological deficits or any other positive neurological findings. GCS - E4V5M6

\section{Management}

The patient was shifted to OT and multipara monitors were applied. The patient was induced with Fentanyl $40 \mathrm{mcg}$, Propofol $50 \mathrm{mg}$ and Atracurium $10 \mathrm{mg}$. She was intubated with a cuffed $5.5 \mathrm{~mm}$ ID endotracheal tube and surgery was started.

During the surgery, the surgeons found a small gap in parietal bone large enough for a small bullet to pass and also the dura underneath this area showed a small rent. The bullet was retrieved from her brain with help of microscope and c-arm intraoperatively. The duration of surgery was around 4 hours and the child was extubated at the end of surgery. The post op course of the patient remained uneventful and she was discharged on fourth postoperative day.

Images 4 shows presence of Rent in Dura (arrow) and entry point in brain
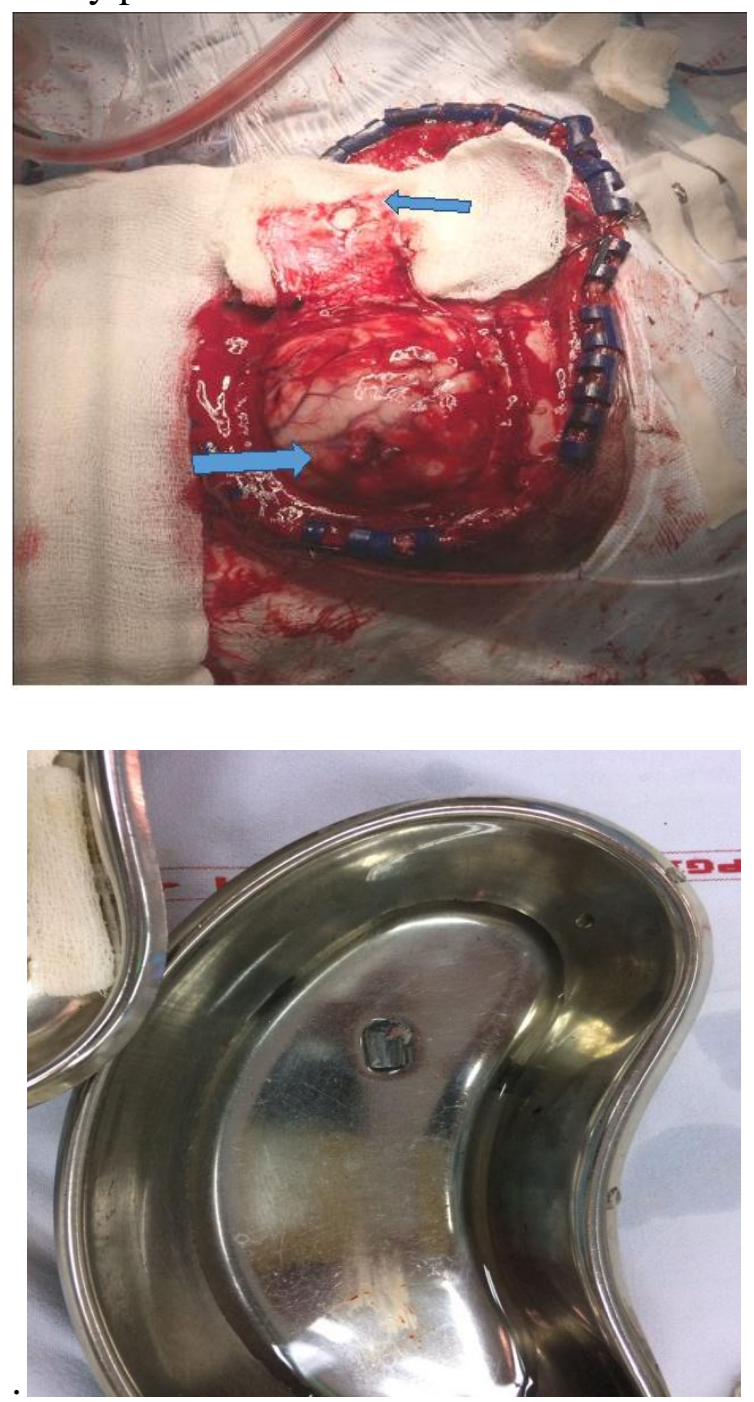

\section{Discussion}

To our knowledge, this is the first case report of a projectile bullet entering into the cerebrum of a pediatric patient and causing no neurological deficit in the patient. The patient was operated only to prevent the possibility of formation of cerebral abscess and to confirm the presence of bullet inside the cerebrum since the history given by the patient was in no way suggestive of a fire 
arm injury. Also, bullets left in body can be a source of lead and can manifest as lead toxicity ${ }^{[1,2]}$.

Bullet injury to brain normally presents as an emergency with high mortality rates. Also, the prognosis of a penetrating brain injury is said to be worse as compared to closed head injury ${ }^{[3]}$. We presume that our patient was hit by a bullet which was fired in air and was probably on its way down to earth and therefore our patient had no sequelae of bullet injury to brain, primarily because of the low velocity of projectile bullet on its way back to earth. Firing in air with firearms remains a common occurrence in north India during wedding ceremonies and often leads to disastrous results. Despite the efforts of law enforcement agencies, these injuries unfortunately continue to be frequently encountered in large trauma centres as well as in large community emergency departments ${ }^{[4]}$. Bullet injuries to brain are currently considered as most severe type of bullet injuries with survival rates of only $7-15 \%{ }^{[5]}$. It has been said that about $90 \%$ of the victims die before prior to reaching at the hospital care, and for those who survive and make it to the hospital, further about $50 \%$ die in the emergency ${ }^{[6,7]}$. Our patient was lucky to have managed to escape a bullet injury to brain without showing any symptoms or suffering any deficits. Had the bullet penetrated around 1 inch more into the brain, it would have reached the region of brainstem and could have caused life threatening injuries.

\section{Conclusion}

GCS on admission, impact of bullet and its trajectory and pupillary reactions are significant determinant of outcome. Carefully planned balanced anesthesia in accordance to radiological findings is of significant importance.

\section{Declaration of patient consent}

The authors certify that they have obtained all appropriate consent forms, in which the, patients attendant has given his consent for his child's images and other clinical information to be reported in journal. The attendant understands the name and initials will not be published and due efforts will be made to conceal identity, but anonymity cannot be guaranteed.

\section{Conflict of interest: Nil}

\section{Source of support and sponsorship: Nil}

\section{References}

1. Bronvin S: Etiologie de la colique de plomb. Union Med 1867;3:89

2. Ellis C: A case of probable lead poisoning, resulting fatally from a bullet lodged in the knee joint twelve years previously. Boston Med Surg J 1874;91:472

3. Part 2.Prognosis in penetrating brain injury. J Trauma.2001; 51: S44- 86

4. Esposito DP, Walker JP.Contemporary management of penetrating brain injury. Neurosurg Q. 2009;19:249-54

5. Selden BS, Goodman JM, Cordell W, Rodman GH, Jr., Schnitzer PG. Outcome of self-inflicted gunshot wounds of the brain. Ann Emerg Med. 1988;17(3):24753

6. Shaffrey ME, Polin RS, Phillips CD, Germanson T, Shaffrey CI, Jane JA. Classifcation of civiliancraniocerebral gunshot wounds: a multivariate analysis predictive of mortality. J Neurotrauma. 1992;9 Suppl 1:S279-85

7. Cavaliere R, Cavenago L, Siccardi D, Viale G. Gunshot wounds of the brain in civilians. Acta Neurochir (Wien). 1988;94(3-4):133-6. 